\title{
MATERIAL REMOVAL MECHANISMS ANALYSIS IN THE FINISHING MACHINING OF ENGINEERING CERAMICS
}

\author{
Changhe $\mathrm{Li}^{1,2}$, Guangqi Cai ${ }^{1}$ \\ 'School of Mechanical Engineering \& Automation, Northeastern University, China; Email: \\ sy_lichanghe@163.com. ${ }^{2}$ Inner Mongolia university for Nationalities, China
}

\begin{abstract}
According to the critical size ratio for the characteristic particle size to film thickness between grinding wheel and workpiece, the machining mechanisms in abrasive jet precision finishing with grinding wheel as restraint of advanced engineering ceramic can be categorized into three states, namely, two-body lapping, three-body polishing, abrasive flow jet machining. The critical condition of two-body lapping to three-body polishing transition was analyzed. The single particle material removal modes of two-body lapping, three-body polishing, abrasive flow jet machining were proposed. Experiments were conduced in the refitted surface grinder for academic modes verification. It was found that experimental results were agreement with theoretical modes and the modes validity were verified.
\end{abstract}

Key words: Material Removal Mechanisms, Free Abrasive, Grinding Wheel as Restraint, Two-body Machining, Three-body Polishing Process, Engineering Ceramic Machining

\section{INTRODUCTION}

The conventional grinding of engineering ceramic makes surface defects such as micro-crack, tensile residual stresses and burnout because of high grinding zone temperatures. Authors invent a newly abrasive jet precision finishing method, which inject slurry of abrasive and liquid solvent to grinding zone under haven't cut-deep infeed condition when accomplished workpiece grinding. The abrasive particles with grinding wheel as restraint are driven and energized by the rotating grinding wheel and liquid hydrodynamic pressure and increased slurry speed between grinding wheel

This project is supported by the National Natural Science Foundation of China under the grant No.50475052.

Please use the following format when citing this chapter:

$\mathrm{Li}$, Changhe, Cai, Guangqi, 2006, in International Federation for Information Processing (IFIP), Volume 207, Knowledge Enterprise: Intelligent Strategies In Product Design, Manufacturing, and Management, eds. K. Wang, Kovacs G., Wozny M., Fang M., (Boston: Springer), pp. 729-734. 
and work surface. The method can either require high form accuracy or attain free damage finishing surface. The goal of this project is establish the foundationally academic system of abrasive jet precision finishing by theoretical and experimental investigation ${ }^{1,2}$.

\section{THE MACHINING THEOREM}

\subsection{Two-body lapping}

The abrasive powder is mixed with a fluid carrier to form a slurry which is turned into the gaps between wheel and workpiece. A schematic of the process is showed in Fig.1. In the abrasive polishing begin, because of the grinding wheel and workpiece clearance is too small, the abrasives between wheel and workpiece are forced into wheel surface pore under liquid hydrodynamic pressure and grinding wheel drag. Because the two force will not be collinear, form a couple tending to totate the particle ${ }^{3,4}$. The sequence of events is illustrated in Fig.2(a) to (c). The particle continues to rotate until the blunt corner makes contact with the work Fig.2(d). In the condition, there is no impetus to cause further rotation and so the particle will tend to remain at the inclination similar to abrasive two-body machining 5 .

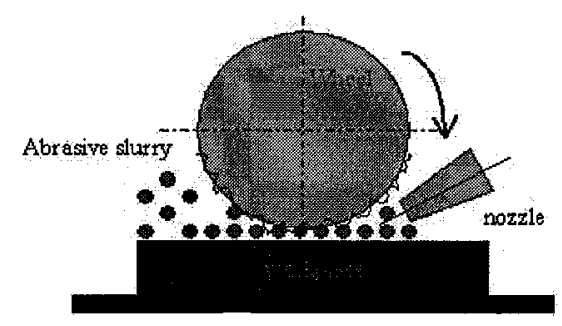

Figure 1.The schematic of abrasive jet finishing.
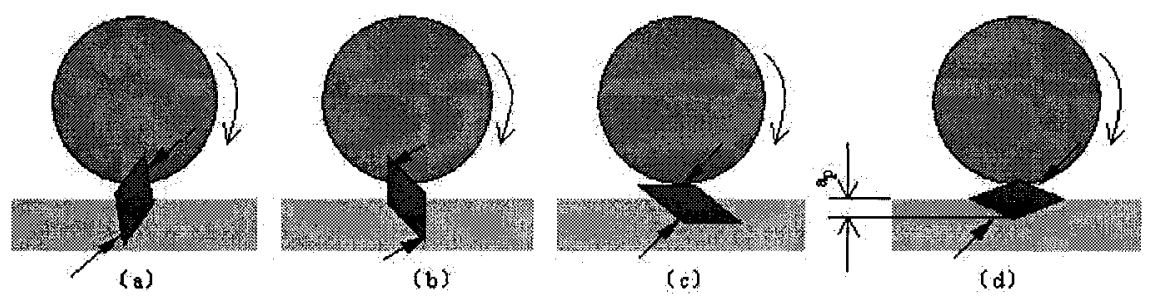

Figure 2. Abrasive movement analyse in two-body process. 


\subsection{Three-body polishing}

With polishing circles increasing, abrasive size gradually diminished and work surface micro-protrusion was removed. The film thickness is increasing lead to the size rate that the characteristic particle size to film thickness is reduce. The particle may rotate sufficiently until lose contact with the work surface, Fig.3.The machining mode is three-body process in which particles are able to tumble and rotate between the wheel and piecework.

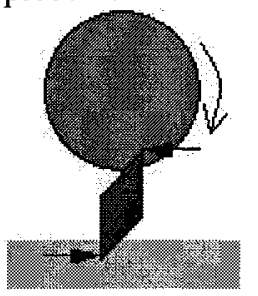

(a)

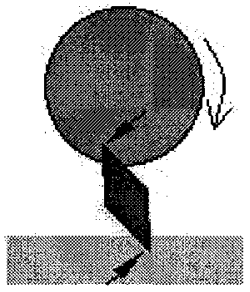

(b)

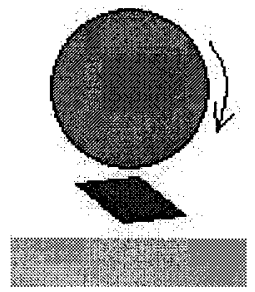

(c)

Figure 3. Abrasive movement analyse in three-body process

\subsection{The transition critical condition}

Since the abrasives are mixed with a fluid carrier to form a slurry and uniformly suspended in the slurry fluid, it is possible that there are several thousand particles present in the gap at any moment. They are likely to be several tens of particle diameters apart, and it is reasonable to think of them acting independently of each other. Therefore, we developed a transition mode from two body lapping to three body polishing, to consider the mechanics of a single representative particle. In the study, the abrasive particle as a long prism with a cross-section which is rhombic in shape. The shortest diagonal of the cross-section is $\mathrm{D}$ and $h_{g}$ is the smallest film thickness. The rate of $\mathrm{D}$ and $h_{g}$ is defined as the critical size rate. when the critical size rate is larger than 1 , the machining mode is two-body lapping. On the other hand, the machining mode is three-body polishing ${ }^{6}$.

\section{EXPERIMENTAL SETUP}

The machining system of the experiments is composed of a rotating grinding wheel and a work between which the slurry was filled in by the nozzle, shown in Fig. 1. The wheel type is WA60J8V, which have diameter $240 \mathrm{~mm}$ and $26 \mathrm{~mm}$ width. The grinding wheel main axis revolution are $2880 \mathrm{rpm}$ and 
the nozzle supply slurry pressure are $3 \times 10^{3} \mathrm{~Pa}$. The slurry is a mixture of abrasive particles and liquid solvent. The abrasive particle is $\mathrm{W}_{7} \mathrm{AI}_{2} \mathrm{O}_{3}$ with primary grain size of $5 \sim 7 \mu \mathrm{m}$. Three types weight percentage grain to slurry are used as the solvents, which are the $5 \% ; 10 \% ; 15 \%$. The workpiece material is alumina ceramic which is machined up-grinding from 10 circles to 40 circles in the experiments. The specimens have dimensions of $50 \times 25 \times 15 \mathrm{~mm}$. The work surface roughness values are measured with a Talysurf instrument ${ }^{7}$.

\section{RESULTS AND DISCUSSION}

\subsection{SEM examinations}

With machining circles increasing, workpiece surface micrographs changing as Fig.4 showed. As might be expected, the work surface was found to be the most aggressive of the abrasives, in that it produced the greatest removal volumes and directionality groove(Fig.4a) at machining circles is 10 (workpiece move to-and-fro one defined as one circles). At the same time, the critical size rate is larger than 1, therefore, the machining mode is two-body lapping; When the machining circles increased to 20 , the workpiece surface not only produced uniformity groove, but with very little sign of random pits. As the discussed above, the machining mode is mixed of two-body lapping and three-body polishing(Fig.4b). When machining to 30 circles, the characteristic particle size to film thickness rate is lower than 1 because of abrasive worn and workpiece surface micro-protrusion removed. The surface produced randomly discontinuous micro-pit absolutely(Fig.4c) and the phenomenon is defined as three-body polishing machining.
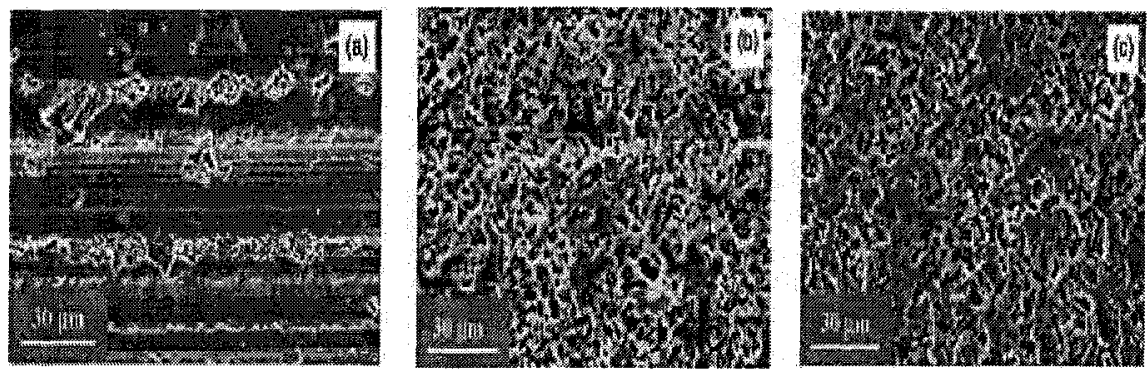

Figure 4. SEM images of abrasive jet process on different machining circles 


\subsection{Surface roughness}

The values of surface roughness of the polishing surface are plotted in Fig.5. It is seen that for all the three percentage concentration the surface roughness decrease with the machining circles increasing. Before 20 cycles, the roughness improvement is low because the machining mode is two-body machining and workpiece surface with continuous and parallel micro-groove. On the other hand, the workpiece surface roughness value obviously diminish after 20 cycles to all abrasive concentration. From the Fig.5, it can be inferred that $15 \%$ concentration of abrasive roughness value is larger than $10 \%$ concentration of abrasive. With higher concentration, more abrasive grains come into contact with the workpiece resulting in more abrasion, hence higher Ra value.

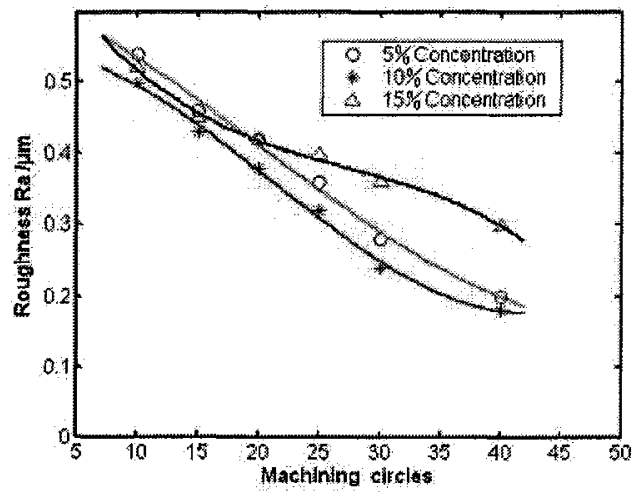

Figure 5. Effect of different abrasive concentration on surface roughness values

\section{CONCLUSION}

The material removal mechanisms are investigated according to the critical size rate. The machining mechanisms are combined with two-body lapping and three-body polishing. Experiments were performed in the refited surface grinder for academic modes verify. It was found that workpiece surface roughness gradually diminish with machining cycles increasing, but the roughness decrease is low before 20 cycles. The micrograph showed, the machined surface from micro-groove to random pits transition with machining process. experimental results were agree with academic modes and the modes validity were verified. 


\section{REFERENCES}

1. LI Chang-he, Cai Guang-qi and LI Qi,Generating mechanism of surface morphology finished by abrasive jet with grinding wheel as restraint, Journal of Northeastern University (natural science), 2005,vol.26(6), pp.578-581.

2. C.H.Li, G.Q.Cai and S.C.Xiu,Material removal model and experimental verification for abrasive jet precision finishing with wheel as restraint, Key Engineering Materlials, 2006, vols. 304-305, pp. 555-559.

3. Chang Y P, Hashimura M, Dornfeid D A,An investigation of material removal mechanisms in lapping with grain size transition, Journal of Manufacturing Science and Engineering, 2000,vol.122, pp.413-419

4. Chauhan R, Ahn Y, Chandrasekar S,Mechanisms of abrasive wear in lubricated contacts, Wear, 1993, vols.162-164, pp.246-257

5. Buijs M, Korpel-van Houten K,Three-body abrasion of brittle materials as studied by lapping, Wear, 1993, vol.166, pp.237-245

6. Li Changhe, Cai Guangqi and Yuan Suoxian, Material removal model for abrasive jet precision finishing restricted by abrasive wheel, Transactions of the Chinese Society for Agricultural Machinery, 2005,vol.36(11),pp.132-135.

7. Li Changhe,Cai Guangqi,Li Qi,et al. Investigation on material removal mechanism for abrasive jet precision finishing with grinding wheel as restraint, China Mechanical Engineering, 2005,vol.16(23), pp.2116-2119 